\title{
Faktor-Faktor yang Mempengaruhi Keberkesanan Amali Kerja Kayu dari Perspektif Pelajar Sekolah Menengah Vokasional di Provinsi Acheh
}

\author{
Lailan Fachrah, Nor Azlina Hasbullah*, Ashah Ab Rahman
}

Fakulti Pendidikan Teknikal dan Vokasional, Universiti Pendidikan Sultan Idris, 35900 Tanjung Malim, Perak, Malaysia

*Corresponding author: azlina.h@fptv.upsi.edu.my

\begin{abstract}
This study aims to identify factors that influence the effectiveness of practical woodworking and determine the effectiveness of practical woodworking from the perspective of students of secondary vocational schools in the province of Aceh. Factors studied were the workshop equipment, safety workshops, teaching skills, the workshop environment and student interest. This study was designed to investigate the significant differences concerning factors woodworking practical effectiveness based on demographic factors. A total of 130 respondents were randomly selected from six vocational schools in the province of Aceh. The instrument consists of a set of questionnaire consisting of 49 items and distributed to second level students. Data analysis using the two types of statistics, namely descriptive statistics and statistical inference. The results showed no significant difference between factors woodworking practical effectiveness based on demographic factors except the income level of parents and the parents of the respondents work. The results of multiple linear regression analysis stepwise method found that only four factors (environmental factors workshops, the students interest, the skills of teachers and workshop equipment factors) that affect the practical effectiveness of woodworking with the correlation coefficient $\mathrm{R}=0.779$. This shows there is a significant effect of the four factors, the effectiveness of practical woodworking, accounting for $60.6 \%\left(\mathrm{R}^{2}=0.606\right)$ changes in the variance in effectiveness of hands-on woodworking, and between the four factors, the workshop environment is the factor that most influences the effectiveness practical woodworking by contributing $43.3 \%\left(\mathrm{R}^{2}=0.433\right)$ of the variance in effectiveness of practical woodworking. The main implication of this study is the need for attention from the authorities to be more serious in efforts to improve the facilities and infrastructure in the workshop as well as security issues in practical workshops so that the effectiveness of the woodwork to be more robust.
\end{abstract}

Keywords: Effectiveness practice; wood work; workshop environment

\begin{abstract}
Abstrak
Kajian ini bertujuan untuk mengenal pasti faktor-faktor yang mempengaruhi keberkesanan amali kerja kayu dan menentukan tahap keberkesanan amali kerja kayu dari perspektif pelajar sekolah menengah vokasional di provinsi Acheh. Faktor-faktor yang dikaji ialah faktor kelengkapan bengkel, keselamatan bengkel, kemahiran guru, persekitaran bengkel dan minat pelajar. Kajian ini juga direkabentuk untuk mengkaji perbezaan yang signifikan mengenai faktorfaktor keberkesanan amali kerja kayu berdasarkan faktor-faktor demografi. Sebanyak 130 responden telah dipilih secara rawak dari enam buah sekolah menengah vokasional di provinsi Acheh. Instrumen kajian terdiri daripada satu set soal selidik yang terdiri daripada 49 item dan diedarkan pelajar tingkatan kedua. Analisa data menggunakan dua jenis statistik, iaitu statistik deskriptif dan statisik inferensi. Hasil kajian menunjukkan tidak terdapat perbezaan yang signifikan di antara faktor-faktor keberkesanan amali kerja kayu berdasarkan faktor demografi kecuali tahap pendapatan ibu bapa dan pekerjaan bapa daripada responden. Hasil dari analisis regresi linear berganda metode stepwise mendapati bahawa hanya empat faktor (faktor persekitaran bengkel, faktor minat pelajar, faktor kemahiran guru dan faktor kelengkapan bengkel) yang mempengaruhi keberkesanan amali kerja kayu dengan nilai pekali korelasi $\mathrm{R}=$ 0.779. Ini menunjukkan terdapat pengaruh yang signifikan daripada ke empat faktor keberkesanan amali kerja kayu dengan menyumbang sebanyak $60.6 \%$ $\left(\mathrm{R}^{2}=0.606\right)$ perubahan varians dalam keberkesanan amali kerja kayu, dan di antara keempat-empat faktor tersebut, persekitaran bengkel adalah faktor yang paling mempengaruhi keberkesanan amali kerja kayu dengan menyumbang $43.3 \%\left(\mathrm{R}^{2}=0.433\right)$ perubahan varians dalam keberkesanan amali kerja kayu. Implikasi utama kajian ini ialah perlunya perhatian dari pihak yang berkuasa untuk lebih serius dalam usaha penambahbaikan kemudahan dan prasarana di dalam bengkel serta masalah keselamatan dalam bengkel agar keberkesanan amali kerja kayu menjadi lebih mantap.
\end{abstract}

Kata kunci: Keberkesanan amali; kerja kayu; persekitaran bengkel

(C) 2017 Penerbit UTM Press. All rights reserved

\subsection{PENGENALAN}

Pendidikan memainkan peranan dalam menghasilkan kualiti sumber tenaga manusia. Seperti yang dinyatakan dalam Undang-Undang Negara Indonesia Nombor 20 Tahun 2003 yang berkaitan dengan Sistem Pendidikan Nasional: "Manusia memerlukan pendidikan dalam kehidupannya. Pendidikan merupakan usaha agar manusia dapat mengembangkan potensi dirinya melalui proses pembelajaran atau cara lain yang dikenali dan diakui oleh masyarakat". Pendidikan merupakan suatu hal yang dapat mengubah nasib masyarakat sesuatu 
bangsa.Pendidikan telah dijadikan komponen penting dalam agenda pembangunan kerana fungsi dan peranannya yang utama dalam membentuk dan melengkapkan sumber manusia yang berpengetahuan sebagai tenaga penggerak yang menyumbang kepada pembangunan tersebut (Abdul Halim Ali, Raja Ahmad Shalaby Raja Hassan, \& Zuber Zain, 2005). Dalam konteks zaman moden ini, tentunya pendidikan akan terus menjadi komponen penting yang menyumbang kepada kemajuan dan keutuhan bangsa. Apalagi dengan kecanggihan teknologi hari ini, tenaga manusia yang berkualiti daripada segi pengetahuan dan nilai-nilai murni semakin ramai diperlukan (Abdul Halim Ali et al., 2005).

Perkembangan global akhir-akhir ini telah menuntut banyak perubahan di setiap aspek kehidupan, baik dari segi ekonomi, pendidikan, politik, sosial dan budaya. Carnoy (1999), menyatakan bahawa potensi pengaruh daripada globalisasi adalah banyak dan mendalam dan memiliki konsekuensi yang besar untuk pekembangan sistem pendidikan, yang belum sepenuhnya dinilai. Globalisasi bermakna lebih banyak persaingan, tidak hanya dengan perusahaan lain di kota atau wilayah yang sama, melainkan juga antar bangsa, tidak terbatas pada batas nasional. Era persaingan global ini memberikan impak berganda. Di satu sisi, era globalisasi membuka kerjasama yang seluas-luasnya antara negara, namun di sisi lain merupakan era persaingan antarabangsa yang semakin sengit. Negara maju, seperti Amerika Syarikat, Jepun, dan China dijangkakan akan banyak mengambil manfaat dari era perdagangan bebas. Sedangkan bagi negara berkembang, seperti Indonesia, hal ini merupakan satu cabaran utama, kerana harus lebih meningkatkan daya saing dengan membentuk keunggulan persaingan di semua sektor, baik sektor produk maupun perkhidmatan dengan mengenengahkan kemampuan sumber manusia yang berkualiti, teknologi dan kemampuan mengurus yang baik (Pavlova, 2009).

Dalam menghadapi persaingan global tersebut, pendidikan vokasional adalah salah satu penyelesaian yang tepat bagi bangsa Indonesia untuk terus berupaya meningkatkan sumber manusia yang berkualiti dengan menekankan penguasaan kompetensi baik bagi guru mahupun bagi pelajarnya. Hal ini sesuai dengan visi sekolah menengah vokasional (di Indonesia, namanya Sekolah Menengah Kejuruan/SMK), iaitu wujudnya SMK bertaraf antarabangsa, menghasilkan graduan yang memiliki jati diri bangsa, mampu mengembangkan keunggulan tempatan dan bersaing di pasaran global (Direktorat Pembinaan Sekolah Menengah Kejuruan, 2011). Para pelajar memerlukan program yang dapat memberikan keterampilan, pengetahuan, sikap kerja, pengalaman, wawasan, dan jaringan yang dapat membantu mendapatkan pekerjaan yang sesuai dengan pilihan kariernya (Billet, 2009). Hal ini sesuai dengan Peraturan Pemerintah Republik Indonesia Nombor 29 Tahun 1990 Bab I fasal 1 iaitu: "Pendidikan menengah vokasional adalah pendidikan pada peringkat pendidikan menengah yang mengutamakan penyiapan pelajar untuk memasuki lapangan kerja serta mengembangkan sikap profesional". Lebih lanjut Peraturan Pemerintah Nombor 73 Tahun 1991, pasal 3 ayat 6 menyatakan bahawa: "Pendidikan vokasional merupakan pendidikan yang mempersiapkan pelajarnya untuk dapat bekerja dalam bidang tertentu".Pendidikan menengah vokasional menjurus kepada bidang khas, agar pelajar boleh memiliki ketrampilan dan keahlian yang khusus, seperti perniagaan, pembuatan, pertanian, kerumahtanggaan, otomotif, telekomunikasi, elektrik, bangunan, kerja kayu dan sebagainya.

Menurut Ramlee (2012), aspirasi transformasi pendidikan vokasional adalah untuk membuka jalan ke arah melahirkan modal insan yang relevan dengan keperluan semasa serta mampu menghadapi persaingan global. Dasar Pendidikan Vokasional adalah untuk memenuhi keperluan tenaga negara dengan cara memperkemaskan sistem pendidikan vokasional ke arah teknikal. Strategi pelaksanaan termasuk: (a) menambah tempat belajar di pendidikan teknikal dan vokasional; (b) mempelbagai kursus teknikal dan vokasional yang sesuai dengan keperluan negara; dan (c) mengkaji sistem sedia ada daripada masa ke masa. Dalam persaingan budaya global pendidikan vokasional semestinya mempunyai hala tujuan yang jelas, identiti dan pegangan yang kukuh.Begitu juga halnya dengan daerah Acheh, yang merupakan salah satu provinsi di Negara Indonesia. Provinsi ini sedang berupaya untuk meningkatkan kualiti pendidikannya dalam semua bidang. Salah satu upaya yang dilakukan iaitu dengan memperbanyakkan sekolah menengah vokasional (kejuruan) di provinsi Acheh. Seperti yang dilaporkan dalam akhbar, Serambi Indonesia, pada 17 Februari 2013 bahawa Kepala Dinas Pendidikan Acheh, Anas M Adam, MPd mengatakan, hingga sekarang jumlah Sekolah Menengah Kejuruan (SMK) di Acheh ialah sebanyak 155 unit sementara Sekolah Menengah Atas (SMA) sebanyak 427 unit di seluruh Acheh. Pada masa hadapan Pemerintah Acheh akan lebih menumpukan kepada pembangunan sekolah kejuruan (vokasional). Hal ini bagi memenuhi tenaga kerja yang berkualiti yang semakin ramai diperlukan dalam bidang perusahaan dan industri.

Bagi menyokong hal ini, keberkesanan dalam proses pembelajaran dan pengajaran di sesebuah sekolah menengah vokasional adalah hal penting yang harus dilakukan, kerana ia mempunyai peranan dalam membina ilmu pengetahuan. Hasil daripada keberkesanan tersebut akan memberi pengaruh positif terhadap tingkah laku seseorang pelajar secara kekal (Siti Atiqah, 2008). Dalam pembelajaran aliran teknikal dan vokasional, bukan hanya pendekatan teori sahaja diterapkan, tetapi pendekatan amali lebih dititikberatkan. Pendekatan amali biasanya dilakukan di bengkel dengan kemudahan yang cukup lengkap, agar pembelajaran berkesan dan memberikan hasil yang baik.

Walau bagaimanapun, inilah masalahnya, melalui pemerhatian dan laporan yang diperolehi dari Kepala Dinas Pendidikan Provinsi Acheh menyatakan bahawa masalah yang dihadapi Sekolah Menengah Kejuruan di Acheh sekarang ini adalah masih kekurangan guruguru produktif dan kelengkapan bengkel masih kurang. Hal ini seperti yang dilaporkan dalam akhbar, Serambi Indonesia, pada 5 Januari 2013, bahawa Kepala Dinas Pendidikan Acheh, Anas M. Adam, MPd mengatakan bahawa guru - guru produktif yang mengajar di SMK di daerah ini masih kurang, banyak guru SMK sekarang ini mengajar tidak sesuai bidangya. Selain itu, beliau melanjutkan bahawa masalah lainnya terkait kurangnya alatan kerja amali bagi pelajar, sehingga ada yang beranggapan lulusan SMK di Acheh masih kurang ketrampilan dan kemahiran. Selain itu, guru produktif dan kemudahan bengkel tersebut juga merupakan faktor yang menyokong mutu lulusan SMK. Oleh sebab itu, Dinas Pendidikan Provinsi Acheh akan lebih menumpukan kepada menyediakan kemudahan-kemudahan bengkel serta penigkatan mutu guru.

Ramlee (2013), menyatakan tentang masalah kesukaran dalam mendapatkan guru sekolah menengah vokasional yang baik. Guru sekolah menengah vokasional umumnya tidak memiliki pengalaman industri yang cukup, sedangkan pengalaman itu diperlukan untuk menaikkan kredibiliti program pendidikan vokasional. Dari sudut lain, gaji dan kesejahteraan guru dikatakan sebagai masalah utama. Gaji yang sedikit, kemudahan yang tidak mencukupi, dan persekitaran pekerjaan yang tidak kondusif disebut sebagai beberapa faktor yang boleh menjejaskan prestasi guru dan akhirnya kualiti sekolah menengah vokasional itu sendiri. Siti Atiqah (2008) menyatakan faktor keselamatan dan pengurusan bengkel amat penting dalam memastikan pengajaran dan pembelajaran berjalan secara efektif. Berdasarkan penelitian Sugiyono (2013), hasil pemerhatian sementara ke sekolah mendapati masalah yang diperolehi dalam pembelajaran amali kerja kayu adalah hasil kerja graduan yang berkualiti masih belum mencapai standard persaingan lulusan yang sesuai seperti yang diharapkan oleh industri serta kurangnya semangat pelajar dalam melaksanakan amali kerja kayu. 


\subsection{SOROTAN LITERATUR}

Pengajaran merupakan aktiviti menyampaikan isi pengajaran, disamping memotivasikan pelajar supaya bersedia untuk belajar, mengurus mereka supaya mempunyai disiplin diri serta menggerakkan mereka dengan aktiviti dan interaksi yang positif (Mok, 2000). Terdapat berbagai perkara yang berlaku semasa pengajaran, dan suatu pengajaran tidak akan sama dengan suatu pengajaran lain. Guru akan berdepan dengan situasi yang berbeza antara setiap pengajaran yang dilaluinya. Pembelajaran pula dilihat sebagai suatu proses memperoleh dan mengekalkan pengetahuan, dan tidak kurang juga yang melihatnya sebagai proses memperoleh kemahiran, malah ada yang berpendapat pembelajaran ialah proses memahami dan bertindak balas terhadap persekitaran. Kualiti pembelajaran dan pengajaran di sekolah menengah vokasional amat berpengaruh bagi melahirkan tenaga mahir yang berkualiti. Oleh itu, pembelajaran di bengkel di mana para pelajar vokasional mendapat pendidikan formal dalam bidang kemahiran perlulah ditingkatkan lagi keberkesanannya dan kualitinya (Siti Atiqah, 2008). Bidang kerja kayu adalah salah satu bidang aliran vokasional yang tidak tertumpu kepada pembelajaran berbentuk teori sahaja tetapi juga melibatkan pembelajaran berbentuk amali di bengkel. Bidang ini sangat memerlukan pengetahuan dan juga kemahiran, lebih lagi dalam penggunaan peralatan dalam bengkel. Namun, ia bergantung kepada keadaan kemudahan di dalam sesebuah bengkel itu untuk memastikan pengajaran dan pembelajaran akan berjalan dengan efektif. Tetapi hanya kemahiran dan pengetahuan saja masih belum cukup dalam pelaksanaan pengajaran secara berkesan (Azizi Yahaya dan Wong, 2007). Kualiti dan kemahiran seseorang guru adalah sangat penting dalam meningkatkan keberkesanan terhadap pembelajaran bidang kerja kayu ini. Keberkesanan pengajaran bergantung juga kepada kecekapan guru dalam merancang dan melaksanakan sesuatu pengajaran (Mok, 2002).Pengajaran yang berkesan boleh dirumuskan sebagai satu sistem aktiviti yang dapat mencapai hasil pembelajaran mengikut objektifnya dalam suasana yang sihat, menarik, seronok, bersemangat, demokratik, tenang dan berdisiplin.

Donnelly (1995) menyatakan bahawa kerja amali adalah ciri-ciri yang menonjol dan khas dari ilmu pendidikan, banyak guru sains dan orang lain melihat bahawa kerja amali yang dilakukan pelajar itu sendiri sebagai unsur yang penting dari pengajaran sains yang baik. Kerja kayu merupakan subjek yang menggabungkan kaedah teori dan kaedah amali dalam proses pengajaran dan pembelajaran. Subjek ini akan berkesan sekiranya semua topik yang diajar dalam matapelajaran ini tidak hanya diajar di dalam kelas, namun mesti dipraktikkan secara amali di dalam bengkel. Pengajaran akan mudah berlaku di dalam kelas atau pun bengkel dan objektif pengajaran akan dapat dicapai dengan jayanya, jika pengajaran dan pembelajaran itu sendiri berkesan dan antara pelajar dan guru saling ada komunikasi dan interaksi yang baik. Menurut Teddlie dan Reynolds (2000), keberkesanan sekolah adalah tentang banyak hal yang lebih dari memaksimumkan pencapaian akademik. Pembelajaran, dan cinta pembelajaran; pembangunan peribadi dan keyakinan diri; kemahiran hidup, menyelesaikan masalah dan belajar bagimana untuk belajar; pembangunan pemikir bebas dan yang bulat, individu yang percaya diri di semua peringkat yang tinggi atau lebih tinggi dalam hasil persekolahan yang efektif sebagai kejayaan dalam kisaran disiplin akademik yang sempit.

\section{Faktor Kemudahan di Bengkel}

Kemudahan dan infrastruktur merupakan salah satu aspek penting yang menyumbang kepada kegiatan proses belajar mengajar di sebuah bengkel vokasional. Dengan adanya fasiliti yang lengkap dan memadai, proses pembelajaran dan pengajaran baik teori mahupun amali akan lebih mudah dijalankan dan tujuan pembelajaran akan tercapai dengan maksimum. Jika tujuan pembelajaran tercapai, maka secara langsung akan mempengaruhi pencapaian akademik pelajar. Kemudahan bengkel bermaksud segala sesuatu yang berada di bengkel termasuk peralatan, baik peralatan tangan mahupun peralatan mesin; dan bahan-bahan amali yang mencukupi dan yang menyokong keberkesanan proses pembelajaran dan pengajaran berkaitan amali kerja kayu. Mengikut Irmayanti (2008), proses pembelajaran dan pengajaran di dalam bengkel amali akan tergendala tanpa ada peralatan dan kemudahan yang mencukupi.

\section{Faktor Keselamatan di Bengkel}

Faktor keselamatan merupakan satu aspek yang tidak kurang penting yang dapat menyokong pembelajaran dan pengajaran yang berkesan. Kesedaran akan keselamatan bengkel perlu ditekankan kepada pelajar. Seseorang pelajar yang tidak mempunyai sikap mengutamakan amalan keselamatan bengkel tidak boleh dianggap sebagai pelajar yang berkebolehan dan mahir. Jika pelajar sentiasa mematuhi langkahlangkah keselamatan di tempat kerja, maka kebanyakan kemalangan yang berlaku dapat dielakkan (Ahmad Fuad, 1995). Keselamatan di dalam bengkel adalah tanggungjawab bersama terutamanya pelajar-pelajar yang menggunakan bengkel dalam kerja amali mereka. Ia bukan sahaja dapat menghindarkan diri dari sebarang kemalangan malah dapat membantu kelancaran pengajaran dan pembelajaran yang berkesan, sehingga dapat dicapai tujuan pembelajaran yang maksimal dan dapat mempengaruhi pencapaian akademik pelajar.

Menurut Loganathan (2008), keselamatan adalah suatu situasi yang bebas daripada kemalangan, kecederaan, rasa takut, rasa sakit atau kehilangan yang mana ianya perlu mendapatkan tindakan yang sewajarnya dari semua pihak yang berwenang. Manakala menurut NSW Department of Education and Training (2003), keselamatan adalah hal yang perlu diutamakan, bermakna suatu istilah yang menggambarkan idea bahawa semua aktiviti dan persekitaran yang perlu dikawal untuk mengelakkan kecederaan berlaku kepada semua orang yang berada dalam keadaan itu, terutamanya yang berkaitan dengan sikap dan tanggung jawab peribadi.

\section{Faktor Kemahiran Guru}

Dalam proses pembelajaran guru memegang peranan yang sangat penting. Peranan guru bukanlah hanya berperanan sebagai teladan bagi pelajarnya, namun juga sebagai pengelola pembelajaran (manager of learning). Menurut Morisson (2000), agar pengajaran berkesan, seseorang guru harus mempunyai pengetahuan mengenai mata pelajaran tersebut, pengetahuan tentang cara pengajaran yang berkesan, pengetahuan membina rancangan, pengetahuan mengikut perkembangan pelajar, pengetahuan professional, pengetahuan tentang kurikulum, pengetahuan untuk berkomunikasi dan hubungan antara manusia, pengetahuan mengendalikan kelas, pengetahuan mengajar dalam pelbagai bangsa dan jantina, pengetahuan dalam komuniti dan pengetahuan latar belakang pendidikan. Dengan demikian, 
keberkesanan proses pembelajaran terletak di bahu guru. Oleh kerana itu, keberhasilan suatu proses pembelajaran sangat ditentukan oleh kualiti atau kemahiran guru.

\section{Faktor Persekitaran Bengkel}

Persekitaran berperanan memberi keselesaan kepada pelajar untuk melakukan kerja-kerja amali. Menjaga kebersihan merupakan salah satu aspek yang penting dan perlu dititikberatkan seperti kebersihan diri dan kawasan tempat kerja. Bengkel yang bersih dapat menunjukkan bahawa kerja-kerja yang dijalankan adalah bersih, teratur dan mengikut kaedah yang betul. Walaupun kerja-kerja dalam bengkel melibatkan kerja-kerja yang kotor, seseorang individu yang mempunyai sikap yang baik boleh menjaga kebersihan diri dan persekitarannya (Mohd Rizal \& Rahizah Zahari, 2011). Menurut Khan \& Vickery (1970), ruangan yang disediakan oleh sesebuah bengkel mestilah mengambil kira aspek pencahayaan, peredaran udara dan bunyi bising.

\section{Faktor Minat Pelajar}

Faktor yang juga berperanan dalam menyokong keberkesanan amali kerja kayu adalah faktor minat pelajar. Minat amat berperanan dalam kejayaan bagi sesuatu pembelajaran. Minat merupakan faktor intrinsik iaitu perasaan dalaman yang mendorong kejayaan seseorang. Crow \& Crow (1988) menyatakan bahawa minat merupakan satu elemen yang penting yang menjadi daya penggerak utama yang menjamin kejayaan dalam sesuatu bidang. Minat berkait rapat dengan motif dan gerakbalas emosi hasil daripada pengalaman dan persekitaran. Jika seseorang tidak mempunyai minat yang tinggi dalam sesuatu bidang, ia akan menghalang seseorang untuk memperolehi pencapaian yang cemerlang.

\subsection{METODOLOGI KAJIAN}

Dalam kajian ini reka bentuk penyelidikan yang digunakan adalah reka bentuk kajian tinjauan.Menurut Ramlee Mustapha et al. (2015), kajian tinjauan adalah kaedah yang popular digunakan untuk membuat kajian kuantitatif dalam bidang sains sosial dan pendidikan termasuk dalam bidang pendidikan teknikal dan vokasional. Kajian ini biasanya juga digunakan untuk mengukur persepsi yang berkaitan dengan sesuatu isu, perkhidmatan atau produk. Hal ini sesuai dengan kajian yang penyelidik lakukan, karena penyelidikan ini bersifat kuantitatif. Kajian berbentuk tinjauan memerlukan penyelidik memilih sampel atau keseluruhan populasi dalam usaha menerangkan sikap, pendapat, perangai, atau ciri-ciri yang hendak dikaji (Creswell, 2002). Menurut Kelley et al. (2003) pula, kajian tinjauan adalah kajian yang melibatkan persampelan rawak untuk memilih bilangan responden (sampel size) dari populasi yang sudah ditentukan lebih awal dan diikuti dengan pengumpulan data daripada sampel tersebut. Dalam kajian tinjauan, data dikumpul oleh penyelidik menggunakan instrumen kajian seperti soal selidik dan dianalisis menggunakan kaedah statistik deskriptif dan inferensi yang sesuai. Data yang diperoleh adalah berdasarkan jawapan responden daripada borang soal selidik yang telah diedarkan.

\section{Pengumpulan Data}

Prosedur pengumpulan data dalam kajian ini ialah dengan menghantar borang soal selidik secara langsung kepada 130 orang pelajar kelas 2 bidang kerja kayu di enam buah sekolah menengah vokasional di Provinsi Acheh. Hal ini bagi mengenal pasti responden yang akan mengisi borang soal selidik sesuai dengan kriteria sampel yang telah ditentukan. Sebelum penyelidik melakukan kajian sebenar, kajian rintis perlu dilakukan terlebih dahulu bagi menentukan kesahan dan kebolehpercayaan instrumen.Sebelum borang soal selidik dihantarkan kepada responden, penyelidik mestilah mendapat surat pengesahan untuk melakukan penyelidikan yang diperolehi dari Dinas Pendidikan di Provinsi Acheh.

\subsection{DAPATAN KAJIAN}

\section{Analisis Deskriptif}

Bahagian ini adalah untuk menjawab persoalan kajian mengenai enam domain faktor-faktor keberkesanan amali kerja kayu iaitu faktor kelengkapan bengkel, faktor keselamatan bengkel, faktor kekemahiran guru, faktor persekitaran bengkel, faktor minat, dan keberkesanan amali kerja kayu. Secara umumnya, berdasarkan Jadual 1, menunjukkan bahawa min domain yang paling tinggi $(\mathrm{M}=3.39 ; \mathrm{SP}=0.55)$ adalah domain faktor kemahiran guru dan min yang paling rendah didapati pada domain faktor keselamatan bengkel iaitu min $=2.28$ dan sisihan piawai $=0.58$.

Jadual 1 Min keseluruhan faktor dan keberkesanan amali kerja kayu

\begin{tabular}{lcc}
\hline Faktor dan Keberkesanan Amali Kerja Kayu & Min & SP \\
\hline Domain Faktor Kemahiran Guru & 3.39 & 0.55 \\
Domain Faktor Persekitaran Bengkel & 3.34 & 0.61 \\
Domain Faktor Minat & 3.33 & 0.56 \\
Domain Keberkesanan Amali Kerja Kayu & 3.28 & 0.58 \\
Domain Faktor Kelengkapan Bengkel & 3.29 & 0.63 \\
Domain Faktor Keselamatan Bengkel & 3.22 & 0.63 \\
\hline Skor Purata & $\mathbf{3 . 3 0}$ & $\mathbf{0 . 5 9}$ \\
\hline
\end{tabular}


Analisis Statistik Inferensi

\section{1) Perbezaan Faktor dan Keberkesanan Amali Kerja Kayu Berdasarkan Faktor Demografi}

Seksyen ini adalah untuk mengkaji perbezaan mengenai faktor dan keberkesanan amali kerja kayu berdasarkan demografi terpilih responden Sekolah Menengah Vokasional di Provinsi Acheh. Pembolehubah demografi yang diuji adalah pencapaian peperiksaan akhir tahun bagi mata pelajaran kerja kayu, pendapatan ibu bapa dalam satu bulan, jantina, pekerjaan ibu bapa serta hobi pelajar.

\section{a. Perbezaan Faktor dan Keberkesanan Amali Kerja Kayu Berdasarkan Pencapaian Peperiksaan Akhir Tahun Bagi Mata Pelajaran Kerja Kayu}

Hipotesis Ho1: Tidak terdapat wujud perbezaan yang signifikan antara faktor dan keberkesanan amali kerja kayu berdasarkan pencapaian akademik akhir tahun dalam mata pelajaran kerja kayu.

Dalam menguji hipotesis nol Ho, pengkaji menggunakan ujian-F (ANOVA) untuk mengukur perbezaan faktor dan keberkesanan amali kerja kayu responden berdasarkan pencapaian peperiksaan akhir tahun bagi mata pelajaran kerja kayu.

Ujian - F (ANOVA) menunjukkan keputusan yang tidak signifikan ( $\mathrm{p}=0.15)$. Nilai signifikan yang diperolehi adalah lebih besar daripada aras signifikan yang ditetapkan iaitu $\alpha=0.05$. Ini menggambarkan bahawa tidak terdapat perbezaan yang signifikan mengenai pencapaian peperiksaan akhir tahun bagi mata pelajaran kerja kayu (jadual 2).

Jadual 2 Ujian ANOVA bagi faktor dan keberkesanan amali kerja kayu berdasarkan pencapaian peperiksaan akhir tahun bagi mata pelajaran kerja kayu

\begin{tabular}{|c|c|c|c|c|c|}
\hline $\begin{array}{l}\text { Faktor dan Keberkesanan } \\
\text { Amali Kerja Kayu }\end{array}$ & $\begin{array}{c}\text { Jumlah } \\
\text { Kuasa Dua }\end{array}$ & $\begin{array}{c}\text { Darjah } \\
\text { kebebasan }\end{array}$ & Min Kuasa dua & $\mathbf{F}$ & Sig. \\
\hline Antara Kumpulan & 0.35 & 2 & 0.17 & 1.89 & 0.15 \\
\hline Dalam Kumpulan & 11.92 & 127 & 0.09 & & \\
\hline Jumlah & 12.27 & 129 & & & \\
\hline
\end{tabular}

\section{b. Perbezaan Faktor dan Keberkesanan Amali Kerja Kayu Berdasarkan Pendapatan Ibu Bapa}

Hipotesis Ho2: Tidak terdapat perbezaan yang signifikan faktor dan keberkesanan amali Kerja Kayuberdasarkan pendapatan ibu bapa

Jadual 3 menunjukkan keputusan ujian-F (ANOVA) di mana nilai $\mathrm{p}=0.01$, iaitu lebih kecil daripada aras signifikan yang ditetapkan iaitu $\alpha=0.05$. Ini menunjukkan bahawa nilai $\mathrm{p}$ lebih kecil daripada $\alpha=0.05$. Oleh itu, hipotesis Ho2 dalam kajian ini ditolak. Ini bermakna terdapat perbezaan yang signifikan mengenai faktor dan keberkesanan amali kerja kayu responden berdasarkan pendapatan ibu bapa.

Jadual 3 Ujian ANOVA bagi faktor dan keberkesanan amali kerja kayu berdasarkan pendapatan ibu bapa

\begin{tabular}{cccccc}
\hline $\begin{array}{c}\text { Faktor dan Keberkesanan } \\
\text { Amali Kerja Kayu }\end{array}$ & $\begin{array}{c}\text { Jumlah } \\
\text { Kuasa Dua }\end{array}$ & $\begin{array}{c}\text { Darjah } \\
\text { kebebasan }\end{array}$ & Min Kuasa dua & F & Sig. \\
\hline Antara Kumpulan & 0.85 & 2 & 0.42 & 4.76 & 0.01 \\
Dalam Kumpulan & 11.42 & 127 & 0.09 & & \\
\hline Jumlah & 12.278 & 129 & & & \\
\hline
\end{tabular}

*Signifikan pada $\mathrm{p}>0.05$

\section{c. Perbezaan Faktor dan Keberkesanan Amali Kerja Kayu Berdasarkan Jantina}

Hipotesis Ho3 : Tidak terdapat perbezaan yang signifikan faktor dan keberkesanan amali kerja kayu berdasarkan jantina

Jadual 4 menunjukkan keputusan ujian-t mengenai faktor dan keberkesanan amali kerja kayu responden berdasarkan jantina responden. Hasil analisis ujian $-\mathrm{t}$ menunjukkan keputusan yang tidak signifikan $(\mathrm{p}=0.49)$ pada aras signifikan yang di tetapkan iaitu $\alpha=0.05$. Maka hipotesis Ho3 diterima kerana tidak terdapat perbezaan yang signifikan mengenai faktor dan keberkesanan amali kerja kayu berdasarkan jantina responden. 
Jadual 4 Ujian-t bagi faktor dan keberkesanan amali kerja kayu berdasarkan Jantina

\begin{tabular}{lccccc} 
Faktor dan Keberkesanan Amali Kerja Kayu & $\mathbf{n}$ & Min & SP & t & Sig. \\
\hline Lelaki & 118 & 3.31 & 0.31 & 0.33 & 0.49 \\
Perempuan & 12 & 3.28 & 0.26 & & \\
\hline
\end{tabular}

*Signifikan pada $\mathrm{p}>0.05$

\section{d. Perbezaan Faktor dan Keberkesanan Amali Kerja Kayu Berdasarkan Pekerjaan Bapa}

Untuk melihat perbezaan faktor dan keberkesanan amali kerja kayu, ujian-F (ANOVA) telah digunakan. Hasil analisis akan menentukan samada terdapat perbezaan faktor dan keberkesanan amali kerja kayu berdasarkan pekerjaan bapa responden.

\section{Hipotesis Ho4 : Tidak terdapat perbezaan yang signifikanmengenai faktor dan keberkesanan amali kerja kayu berdasarkan pekerjaan bapa.}

Hasil ujian-F (ANOVA) dalam Jadual 5 menunjukkan bahawa nilai p ialah sebanyak 0.01 pada aras signifikan yang ditetapkan iaitu $\alpha=$ 0.05. Ini menunjukkan bahawa nilai $\mathrm{p}$ lebih kecil daripada $\alpha=0.05$. Maka hipotesis Ho4 dalam kajian ini ditolak. Oleh itu, dapat disimpulkan bahawa terdapat perbezaan yang signifikan mengenai faktor dan keberkesanan amali kerja kayu berdasarkan pekerjaan bapa responden.

Jadual 5 Ujian ANOVA bagi Faktor dan Keberkesanan Amali kerja kayu berdasarkan pekerjaan bapa

\begin{tabular}{|c|c|c|c|c|c|}
\hline $\begin{array}{l}\text { Faktor dan Keberkesanan } \\
\text { Amali Kerja Kayu }\end{array}$ & $\begin{array}{c}\text { Jumlah } \\
\text { Kuasa Dua }\end{array}$ & Darjah kebebasan & Min Kuasa dua & $\mathbf{F}$ & Sig. \\
\hline Antara Kumpulan & 1.41 & 6 & 0.23 & 2.66 & 0.01 \\
\hline Dalam Kumpulan & 10.86 & 123 & 0.08 & & \\
\hline Jumlah & 12.27 & 129 & & & \\
\hline
\end{tabular}

\section{e. Perbezaan Faktor dan Keberkesanan Amali Kerja Kayu Berdasarkan Pekerjaan Ibu}

Hipotesis Ho5: Tidak terdapat perbezaan yang signifikan mengenai faktor dan keberkesanan amali kerja kayu berdasarkan pekerjaan ibu

Untuk menguji faktor dan keberkesanan amali kerja kayu berdasarkan pekerjaan ibu, ujian-F (ANOVA) telah dijalankan. Jadual 6 menunjukkan hasil dapatan ujian iaitu nilai p yang diperolehi adalah sebanyak 0.45 pada aras signifikan yang ditetapkan iaitu $\alpha=0.05$. Ini menunjukkan bahawa nilai $\mathrm{p}$ lebih besar daripada $\alpha=0.05$, maka hipotesis Ho5 ini diterima. Maka dapat disimpulkan bahawa tidak terdapat perbezaan yang signifikan mengenai faktor dan keberkesanan amali kerja kayu berdasarkan pekerjaan ibu responden.

Jadual 6 Ujian ANOVA bagi faktor dan keberkesanan amali kerja kayu berdasarkan pekerjaan ibu

\begin{tabular}{ccccc}
\hline $\begin{array}{c}\text { Faktor dan Keberkesanan } \\
\text { Amali Kerja Kayu }\end{array}$ & $\begin{array}{c}\text { Jumlah } \\
\text { Kuasa Dua }\end{array}$ & Darjah kebebasan & Min Kuasa dua & F \\
\hline Antara Kumpulan & 0.45 & 5 & 0.09 & 0.94 \\
Dalam Kumpulan & 11.82 & 124 & 0.09 & \\
\hline Jumlah & 12.27 & 129 & \\
\hline
\end{tabular}

\section{f. Perbezaan Faktor dan Keberkesanan Amali Kerja Kayu Berdasarkan Hobi Pelajar}

Hipotesis Ho6: Tidak terdapat perbezaan yang signifikan mengenai faktor dan keberkesanan amali kerja kayu berdasarkan hobi pelajar

Untuk menguji samada hobi pelajar mempengaruhi faktor dan keberkesanan amali kerja kayu mereka, ujian - F ANOVA dijalankan. Hasil analisis ujian-F (ANOVA) mendapati nilai $\mathrm{p}$ ialah sebanyak 0.78 manakala aras signifikan yang telah ditetapkan ialah $\alpha=0.05$ (lihat Jadual 7). Oleh demikian, nilai p lebih besar daripada aras signifikan yang telah ditetapkan iaitu $\alpha=0.05$, maka hipotesis nol Ho6 dalam kajian ini diterima. Ini bermakna tidak terdapat perbezaan yang signifikan di antara faktor dan keberkesanan amali kerja kayu berdasarkan hobi responden. 
Jadual 7 Ujian ANOVA bagi faktor dan keberkesanan amali kerja kayu berdasarkan hobi pelajar

\begin{tabular}{|c|c|c|c|c|c|}
\hline $\begin{array}{c}\text { Faktor dan Keberkesanan } \\
\text { Amali Kerja Kayu }\end{array}$ & $\begin{array}{c}\text { Jumlah } \\
\text { Kuasa Dua }\end{array}$ & $\begin{array}{c}\text { Darjah } \\
\text { kebebasan }\end{array}$ & Min Kuasa dua & $\mathbf{F}$ & Sig. \\
\hline 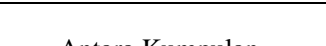 & 0.10 & 3 & 0.03 & 0.35 & 0.78 \\
\hline Dalam Kumpulan & 12.17 & 126 & 0.09 & & \\
\hline Jumlah & 12.27 & 129 & & & \\
\hline
\end{tabular}

*Signifikan pada $\mathrm{p}>0.05$

\section{2) Pengaruh Faktor dan Keberkesanan Amali Kerja Kayu}

\section{Hipotesis Ho7: Tidak terdapat pengaruh yang signifikan di antara domain faktor-faktor keberkesanan amali kerja kayu dengan} keberkesanan amali kerja kayu pelajar

Untuk menguji Hipotesis Ho7, digunakan analisis regresi linier berganda kaedah stepwise. Dapatan kajian berdasarkan jadual menunjukkan bahawa hanya empat faktor yang memberi pengaruh kepada keberkesanan amali kerja kayu. Faktor - faktor tersebut adalah faktor persekitaran bengkel, faktor minat pelajar, faktor kemahiran guru, dan faktor kelengkapan bengkel. Jadual 8 dapat menunjukkan secara signifikan, faktor persekitaran bengkel sahaja menyumbang sebanyak $43.3 \%(\mathrm{r}=0.658)$ perubahan varians dalam keberkesanan amali kerja kayu di kalangan pelajar sekolah menengah vokasional di provinsi Acheh. Kombinasi antara kedua - dua variabel persekitaran bengkel dan minat pelajar menyumbang sebanyak $54.2 \%(\mathrm{r}=0.736)$ perubahan varians dalam keberkesanan amali kerja kayu. Kombinasi antara variabel persekitaran bengkel, minat pelajar, dan kemahiran guru menyumbang sebanyak $59.0 \%(\mathrm{r}=0.768)$ perubahan varians dalam keberkesanan amali kerja kayu. Dan kombinasi antara keempat-empat faktor (faktor persekitaran bengkel, faktor minat pelajar, faktor kemahiran guru, dan faktor kelengkapan bengkel) menyumbang sebanyak 60.6\% ( $\mathrm{r}=0.779)$ perubahan varians dalam keberkesanan amali kerja kayu. Dari hasil analisis tersebut dapat disimpulkan bahawa faktor yang lebih berpengaruh dan signifikan terhadap keberkesanan amali kerja kayu adalah faktor persekitaran bengkel, hal ini kerana sumbangannya paling besar iaitu sebesar $43.3 \%$. Hasil kajian ini disokong dengan pendapat Zuraida (2004) yang menyatakan bahawa persekitaran bengkel yang selesa memberi kesan yang positif terhadap psikologi pelajar, sehingga keberkesanan amali tercapai kerana persekitaran bengkel yang selesa.Merujuk Jadual 9, didapati bahawa nilai signifikan keempat - empat faktor tersebut memenuhi syarat, iaitu $\mathrm{p}<0.05$. Berdasarkan jadual tersebut dapat dilihat bahawa faktor persekitaran bengkel mempunyai nilai signifikan $\mathrm{p}=0.004<\mathrm{p}=0.05$, faktor minat pelajar mempunyai nilai signifikan $\mathrm{p}=$ $0.000<\mathrm{p}=0.05$, faktor kemahiran guru, mempunyai nilai signifikan $\mathrm{p}=0.004<\mathrm{p}=0.05$ dan faktor kelengkapan bengkel mempunyai nilai signifikan $\mathrm{p}=0.023<\mathrm{p}=0.05$.

Jadual 8 Model Summary untuk nilai R dan R Square bagi faktor-faktor yang menyumbang keberkesanan amali kerja kayu

\begin{tabular}{ccccc}
\hline Model & $\mathrm{R}$ & R Square & Adjusted R Square & Std. Error of the Estimate \\
\hline 1 & $.658^{\mathrm{a}}$ & .433 & .428 & .28306 \\
2 & $.736^{\mathrm{b}}$ & .542 & .535 & .25524 \\
3 & $.768^{\mathrm{c}}$ & .590 & .580 & .24267 \\
4 & $.779^{\mathrm{d}}$ & .606 & .594 & .23861 \\
\hline
\end{tabular}

a. Predictors: (Constant), faktor persekitaran bengkel

b. Predictors: (Constant), faktor persekitaranbengkel, faktor minat pelajar

c. Predictors: (Constant), faktor persekitaran bengkel, faktorminatpelajar, faktor kemahiran guru

d. Predictors: (Constant), faktor persekitaran bengkel, faktor minat pelajar, faktor kemahiran guru, faktor kemudahan bengkel

e. Dependent Variable: keberkesanan amali kerja kayu 
Jadual 9 Coefficients faktor-faktor yang mempengaruhi keberkesanan amali kerja kayu

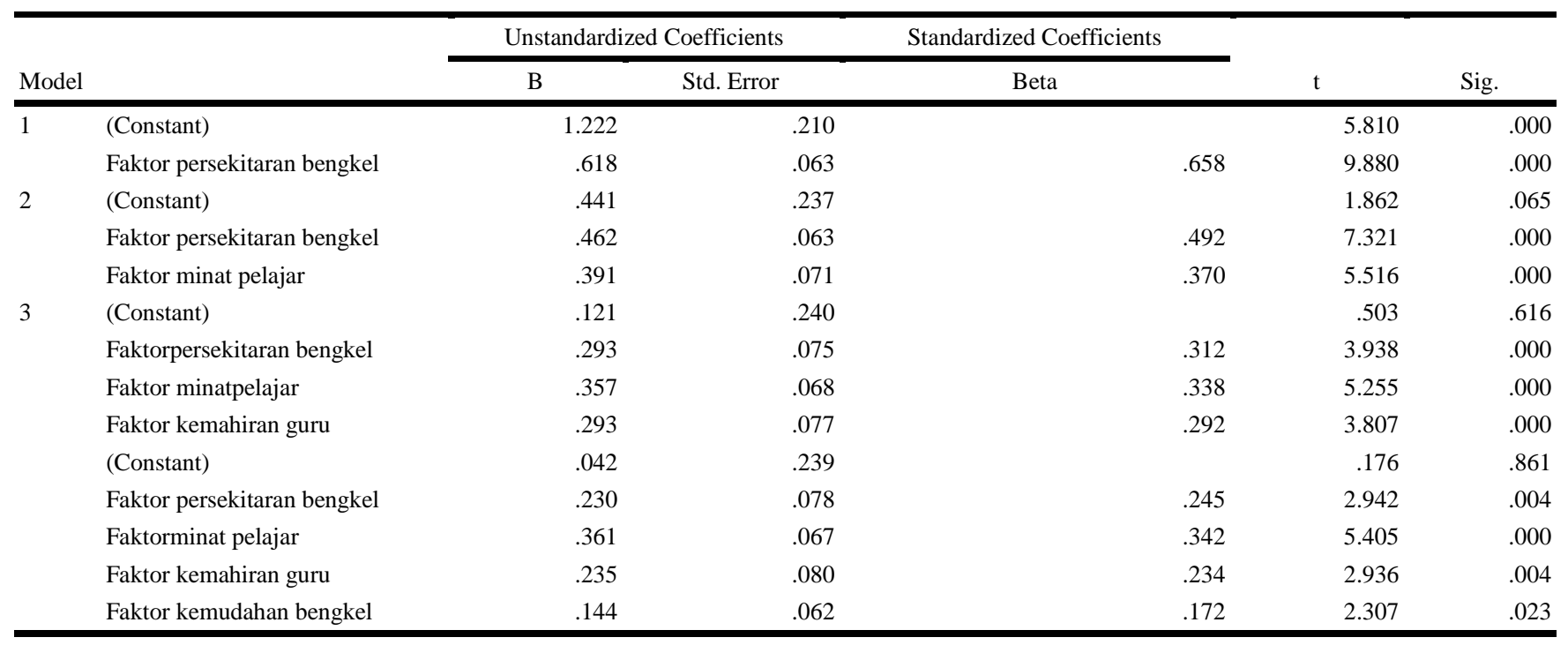

a. Dependent Variable: keberkesanan amali kerja kayu

\subsection{KESIMPULAN}

Kajian yang dijalankan untuk mengenalpasti faktor-faktor yang mempengaruhi keberkesanan amali kerja kayu dari perspektif pelajar sekolah menengah vokasional di Provinsi Acheh. Faktor-faktor yang dikaji adalah faktor kelengkapan bengkel, keselamatan bengkel, kemahiran guru, persekitaran bengkel dan minat pelajar. Kajian ini juga direkabentuk untuk mengkaji perbezaan yang signifikan mengenai faktor-faktor keberkesanan amali kerja kayu berdasarkan faktor-faktor demografi.Hasil kajian menunjukkan tidak terdapat perbezaan yang signifikan di antara faktor-faktor keberkesanan amali kerja kayu berdasarkan faktor demografi kecuali tahap pendapatan ibu bapa dan pekerjaan bapa daripada responden. Hasil dari analisis regresi linear berganda metode stepwise mendapati bahawa hanya empat faktor (faktor persekitaran bengkel, faktor minat pelajar, faktor kemahiran guru dan faktor kelengkapan bengkel) yang mempengaruhi keberkesanan amali kerja kayu dari perspektif pelajar sekolah menengah vokasional di Provinsi Acheh. Berdasarkan hasil kajian ini,diharapkan pada masa-masa hadapan, perlunya perhatian dari pihak yang berkuasa untuk lebih serius dalam usaha penambahbaikan kemudahan dan prasarana di dalam bengkel serta perhatian yang serius dalam masalah keselamatan dalam bengkel agar keberkesanan amali kerja kayu menjadi lebih mantap.

\section{Rujukan}

A. Halim Ali, R. A. S. Raja Hassan dan Z. Zain. (2005). Pak Lah Dalam Pendidikan. Malaysia: Penerbit UPSI.

A. Fuad Md. Idris. (1995). Kepentingan Amalan Keselamatan di Bengkel Kimpalan dan Fabrikasi Logam di Sekolah Menengah Vokasional Kuala Terengganu, Kemaman dan Besut Negeri Terengganu: Satu Tinjauan. Universiti TeknologiMalaysia:Tesis Sarjana Muda.

A. Yahaya \& Wong. (2007). Keberkesanan Proses Pengajaran di Kalangan Guru Kejuruteraan Awam di Sekolah Menengah Teknik. Isu-isu Pendidikan Teknikal Vokasional, Skudai: Penerbit UTM.

Berita dalam akhbar Serambi Indonesia. Banda Acheh: 17 Februari 2013.

C. Teddlie, D. Reynolds. (2000). The International Handbook of School Effectiveness Research. Falmer Press, Taylor\&Francis Group : London\&Newyork.

J. W. Creswell. (2002) Educational Research: Planning, Conducting, and Evaluating Quantitative and Qualitative Research (Second ed.). New Jersey, USA : Pearson-Merril Prentice Hall.

Direktorat Pembinaan SMK. (2014). Data Pokok SMK. Jakarta: Departemen Pendidikan Nasional

Direktorat Pembinaan SMK. (2008). Petunjuk Teknis Penilaian Hasil Belajar SMK. Jakarta: Departemen Pendidikan Nasional.

J. Donnelly. (1995). Curriculum Development in Science: The Lessons of Sc1. School Science Review, 76 (277), 95 - 103.

E. Loganathan. (2008). Amalan Peraturan Keselamatan Bengkel dalam Kalangan Pelajar di Sebuah Institut Kemahiran Mara. Universiti Teknologi Malaysia: Tesis Sarjana Muda.

G. S. Morrison. (2000). Teaching in America. $2^{\text {nd }}$ edition, Needham Heights: Ally and Bacon.

I. Irmayanti. (2008). Kesediaan Pelajar Dalam Pelaksanaan Amali KejuruteraanAwam Di Politeknik. Universiti Tun Hussein Onn Malaysia: Tesis Sarjana.

K. A. Khan,. dan D. J Vickery. (1970). "The Design of Workshop For Asian Second Level Schools". Colombo UNESCO.

K. Kelley, B. Clark, \& B. Brown. (2003). Methodology Matters : Good Practice in The Conduct and Reporting of Survey Research dalam International Journal for Quality in Health Care, 15(3), 261 - 266,

L. D. Crow, A. Crow (1983). Psikologi Pendidikan untuk Perguruan. Dewan Bahasa dan Pustaka, Kuala Lumpur.

M. R. Mohd Said \& R. Zahari. (2011). Kajian Aplikasi Ergonomik Terhadap Pelajar Ketika Melakukan Kerja-Kerja Amali Bengkel Di Kalangan pelajar-Pelajar 4 SPH PKPG Fakulti Pendidikan UTM. Journal of Technical, Vocational \& Engineering Educational, 3, 116-131. ISSN: 2231-7376

M. Pavlova. (2009). Technology and Vocational Education for Sustainable Development: Empowering Individuals for the future. Griffith University, Australia: Springer.

M. Carnoy. (1999). Fundamentals of Educational Planning, Globalization and Educational reform: What Planner Need to Know. Paris: UNESCO.

Peraturan Pemerintah Republik Indonesia, Nombor 29 Tahun 1990.

Peraturan Pemerintah. (1991). Peraturan Pemerintah Republik Indonesia, Nombor 73 Tahun 1991. 
R. Musthapa. (2012). Sekolah Vokasional di Malaysia dan Sekolah Kejuruan di Indonesia. Dalam Prosiding International Seminar Educational Comparative in Competency Based Curriculum between Indonesia and Malaysia. Indonesia University of Education, University Kebangsaan Malaysia dan Universiti Malaya: Bandung.

R. Musthapa. (2013). Sejarah Pendidikan kejuruan di Nusantara: Pembangunan Identiti Negara-Bangsa serta Modal Insan di Malaysia dan Indonesia. Jurnal Kajian Sejarah \& Pendidikan Sejarah, 1, 1, Maret 2013.

R. Mustapha, S. Vengidason, N. Azlina Hasbullah, R. A. Bahtiar \& R. C. Rus. (2015). Reka Bentuk Penyelidikan. Dalam M. Nor Azhari Azman, Ramlee Mustapha. Pendidikan Teknikal \&Vokasional: Pendekatan Penyelidikan, Analisis \& Interpretasi.(). Tanjong Malim, Perak, Malaysia: Penerbit Universiti Pendidikan Sultan Idris, 40-86.

Sugiyono. (2013). Upaya peningkatan Ketrampilan Pelajar membuat Ukiran Kayu pada Kelas X semester 2 SMK Negeri \$ Lhokseumawe. Dalam Prosiding Seminar Nasional Yusuf Benseh. Politeknik Negeri Lhokseumawe: Indonesia

S. Atiqah B. Sharudin. (2008). Faktor yang Mempengaruhi Keberkesanan Pengajaran dan Pembelajaran di Dalam Bengkel Vokasional di Dua Buah Sekolah Menengah Teknik di Negeri Sembilan. Universiti Teknologi Malaysia: Tesis Sarjana Muda.

S.Billet. (2009). Vocational Education: Purposes, Tradition, and Prospect. Griffith University, Australia: Springer.

S. S.Mok. (2000). Pendidikan di Malaysia. Kuala Lumpur. Kumpulan Budiman Sdn. Bhd.

S. S. Mok. (2002). Pedagogi untuk Kursus Diploma Perguruan Semester 3. Subang Jaya: Kumpulan Budiman Sdn Bhd.

Technology Unit, Curriculum K-12 Directorate, NSW Department of Education and Training. (2003). Dalam http://www.curriculumsupport.nsw.edu.au/technology.

Undang-Undang Sistem Pendidikan Nasional Nombor 20 tahun 2003.

Z. Talib (2004). "Tinjauan Kesedaran Keselamatan Bengkel Di Kalangan Pelajar-pelajar Tahun 4 Pendidikan Teknik dan Vokasional di Bengkel Fabrikasi Logam N30 Fakulti Pendidikan”. Universiti Teknologi Malaysia: Tesis Sarjana Muda. 